\title{
Implementasi Pendidikan Karakter Melalui Program 3S (Senyum, Sapa, Salam) Di SMA Negeri 1 Pemali Kecamatan Pemali Kabupaten Bangka
}

\author{
D. Oca Faraeta ${ }^{1}$, Syarifah ${ }^{2}$, Syaiful Anwar ${ }^{3}$ \\ 1IAIN Syaikh Abdurrahman Siddik \\ 2IAIN Syaikh Abdurrahman Siddik \\ 3IAIN Syaikh Abdurrahman Siddik
}

\begin{tabular}{l}
\hline \hline Info Artikel : \\
\hline Diterima 14 Maret 2020 \\
Direvisi 20 April 2020 \\
Dipublikasikan 31 Mei 2020
\end{tabular}

\author{
Kata Kunci: \\ Pendidikan Karakter \\ Implementasi \\ Progam 3 S \\ (Senyum, Sapa, Salam)
}

Keywords:

Character Building

Implementation

3 S Program

(Senyum, Sapa, Salam)

\begin{abstract}
ABSTRAK
Fokus penelitian ini berkenaan dengan implementasi pendidikan karakter melalui program 3S (senyum, sapa, salam). Penelitian ini bertujuan untuk mendeskripsikan implementasi pendidikan karakter melalui program 3S (senyum, sapa, salam) dan untuk memberikan informasi tambahan mengenai faktor pendukung dan penghambat dalam pelaksanaan pendidikan karakter melalui program 3S (senyum, sapa, salam). Implementasi pendidikan karakter melalui program 3S (senyum, sapa, salam) terdapat dalam tiga kegiatan, yaitu: di dalam kegiatan pengembangan diri, di dalam mata pelajaran, dan di dalam kegiatan ekstrakurikuler. Jenis penelitian ini menggunakan metode penelitian kualitatif deskriptif. Hasil penelitian yang telah dilakukan diharapkan dapat membantu guru untuk lebih mengembangkan kegiatan dalam program 3S (senyum, sapa, salam). Berdasarkan hasil penelitian, implementasi pendidikan karakter melalui program 3S (senyum, sapa, salam) sudah terlaksana 85\%. Hasil penelitian ini diharapkan dapat membantu guru untuk mengatasai faktor penghambat dalam implementasi pendidikan karakter melalui program 3S (senyum, sapa, salam) di sekolah
\end{abstract}

\begin{abstract}
The focus of this research relates to the implementation of character education through the $3 S$ program (smile, greetings, greetings). This study aims to describe the implementation of character education through the $3 S$ program (smile, greetings, greetings) and to provide additional information on supporting and inhibiting factors in the implementation of character education through the $3 S$ program (smile, greetings, greetings). The implementation of character education through the $3 S$ program (smiles, greetings, greetings) is included in three activities, namely: in self-development activities, in subjects, and in extracurricular activities. This type of research uses descriptive qualitative research methods. The results of the research that has been done are expected to help teachers to further develop activities in the $3 S$ program (smile, greetings, greetings). Based on the research results, the implementation of character education through the $3 S$ program (smile, greetings, greetings) has been carried out $85 \%$. The results of this study are expected to help teachers overcome the inhibiting factors in the implementation of character education through the $3 S$ program (smile, greetings, greetings) at school
\end{abstract}

\section{Koresponden:(9 pt) \\ D. Oca Faraeta, Email: Divenaochq@gmail.com}

This is an open access article distributed under the Creative Commons Attribution License, which permits unrestricted use, distribution, and reproduction in any medium, provided the original

\section{PENDAHULUAN}

Pendidikan merupakan usaha sadar dan terencana yang dilakukan seseorang dalam mengembangkan potensi dirinya agar bermanfaat bagi kepentingan hidupnya. Menurut Nurani Soyomukti, ${ }^{1}$ pendidikan adalah proses untuk memberikan manusia berbagai macam situasi yang bertujuan sebagai pemberdayaan

${ }^{1}$ Nurani Soyomukti, Teori-teori Pendidikan, (2015):21. 
diri. Dalam Undang-Undang Sisdiknas, ${ }^{2}$ (Sistem Pendidikan Nasional) 2013 (UU RI No. 20 Tahun 2003) Bab I Pasal Imenjelaskan bahwa pendidikan adalah usaha sadar dan terencana untuk mewujudkan suasana belajar dan proses pembelajaran agar peserta didik secara aktif mengembangkan potensi dirinya untuk memiliki kekuatan spiritual keagamaan, pengendalian diri, kepribadian, akhlak mulia, serta keterampilan yang diperlukan dirinya, masyarakat maupun bangsa dan Negara. Lebih jauh Masnur Muslich, ${ }^{3}$ menjelaskan pendidikan merupakan proses internalisasi budaya ke dalam diri seseorang dan masyarakat sehingga membuat orang dan masyarakat menjadi beradab. Pendidikan bukan hanya merupakan sarana transfer ilmu pengetahuan, namun pendidikan juga sebagai sarana pembudayaan. Dari uraian di atas dapat disimpulkan, bahwa pendidikan merupakan usaha terencana untuk mengembangkan semua aspek kepribadian peserta didik. Pendidikan bukan hanya sekedar transfer ilmu, namun pendidikan harus dapat mengubah tingkah laku peserta didik menjadi beradab dan menjadi lebih baik. Tidak dapat dipungkiri bahwa tujuan pendidikan di Indonesia seperti yang tertuang dalam Undang-Undang Sisdiknas (Sistem Pendidikan Nasional) 2013 (UU RI No. 20 Tahun 2003) belum terlaksana secara maksimal. Hal ini dibuktikan dengan adanya kasus bullying di daerah Pontianak yang terjadi pada bulan April 2019 lalu, seorang siswi SMP yang berusia 14 tahun yang dikeroyok dan diduga diserang secara seksual oleh 12 orang siswi SMA. Kekerasan yang dilakukan oleh peserta didik SMA membuktikan sudah tidak adanya sikap saling menghargai lagi antar sesama, kurang berkembangnya nilai cinta sosial di antara mereka. Maka dari itu, pemerintah tidak diam saja untuk memperbaiki moral generasi penerus, Kementerian Pendidikan Nasional (Kemendiknas) berusaha memperbaiki moral generasi penerus dengan merancang sebuah pendidikan karakter.

Dalam hal ini peran sekolah sangat penting untuk mencetak generasi penerus bangsa yang berkarakter. Generasi penerus harus memiliki karakter yang baik. Guru sebagai pendidik diharapkan berinisiatif memperbaiki moral generasi penerus bangsa, sehingga karakter bangsa tidak hilang. Peserta didik adalah generasi yang akan meneruskan perjuangan bangsa dikemudian hari. Karakter peserta didik yang terbentuk dari sekarang akan sangat menentukan karakter bangsa ini. Karakter peserta didik yang terbentuk dengan baik apabila dalam proses pertumbuhan dan perkembangannya mereka mendapatkan cukup ruang untuk mengekspresikan diri secara leluasa. Peserta didik merupakan pribadi yang mempunyai hak untuk tumbuh dan bertumbuh secara optimal sesuai dengan kemampuan masingmasing. ${ }^{4}$ Pendidikan karakter sangat penting untuk diterapkan, karena itulah peneliti tertarik untuk melakukan penelitian tentang pendidikan karakter di Sekolah Menengah Atas (SMA). Seperti yang telah diamati peneliti di SMA Negeri 1 Pemali Kecamatan Pemali Kabupaten Bangka, SMA Negeri 1 Pemali telah melaksanakan program senyum, sapa, salam untuk pendidikan karakter. Peserta didik di SMA Negeri 1 Pemali selalu bersikap sopan santun. Hal ini ditunjukkan dengan peserta didik yang selalu bersalaman ketika guru baru datang dan setiap bertemu dengan orang yang lebih tua.

Berdasarkan hasil wawancara yang telah dilakukan oleh peneliti, bahwa program 3S "senyum, sapa, salam" ini merupakan salah satu kebijakan untuk penguatan pendidikan karakter. Adapun alasan dibentuknya program tersebut adalah untuk memunculkan kembali delapan belas karakter yang mulai tergerus oleh era digital seperti gadget yang mana terjadi pada zaman generasi milenial sekarang. Maka dari itu, SMA Negeri 1 Pemali membuat program 3S "senyum, sapa, salam" yang bertujuan untuk kegiatan pembiasaan. ${ }^{5}$ SMA Negeri 1 Pemali Kecamatan Pemali Kabupaten Bangka mempunyai visi "Menciptakan generasi yang berakhlak, berkarakter, berprestasi, menguasai iptek, dan peduli lingkungan". Untuk mencapai visi tersebut, SMA Negeri 1 Pemali Kecamatan Pemali Kabupaten Bangka melaksanakan program 3S (Senyum, Sapa, Salam) sebagai salah satu sarana pelaksanaan pendidikan karakter.

Berdasarkan latar belakang penelitian yang dijelaskan di atas, perlu dirumuskan permasalahan secara sistematis dan jelas, dalam penelitian ini ada beberapa masalah pokok, yaitu:

1. Bagaimana implementasi pendidikan karakter melalui program 3S (senyum, sapa, salam) di dalam lingkungan SMA Negeri 1 Pemali ?

2. Apa saja faktor pendukung dan penghambat dalam pelaksanaan pendidikan karakter melalui program 3S (senyum, sapa, salam) data, penyajian data, dan penarikan kesimpulan/verifikasi?

\section{METODE}

Jenis penelitian yang peneliti gunakan pada penelitian ini adalah jenis pendekatan kualitatif deskriptif. Penelitian kualitatif adalah penelitian yang bermaksud untuk memahami fenomena tentang apa yang

\footnotetext{
${ }^{2}$ Akhmad Muhaimin Azzet, Pendidikan yang Membebaskan, (2011):15

${ }^{3}$ Masnur Muslich, Pendidikan Karakter Menjawab Tantangan Krisis Multidimensional, (2011):69.

${ }^{4}$ Moh. Haitami Salim, Pendidikan Karakter, (2013):105

${ }^{5}$ Sunandar, Wawancara, (2019)
} 
dialami oleh subjek penelitian, misalnya perilaku, persepsi, motivasi, tindakan dan sebagainya, secara holistik dan dengan cara deskripsi dalam bentuk kata-kata dan bahasa, pada suatu konteks khusus yang alamiah. ${ }^{6}$

Peneliti menggunakan pendekatan kualitatif karena dalam penelitian ini lebih mementingkan proses daripada hasil. Selain itu, permasalahan yang diungkap tidak berkaitan dengan angka-angka, melainkan berupa kata-kata serta gambar yang diolah sedemikian rupa sehingga menghasilkan deskripsi.

Dalam pengumpulan data, peneliti menggunakan beberapa instrumen, antara lain: 1) Wawancara, 2) Observasi, 3) Dokumentasi. Analisis data menurut Miles dan Huberman yang dikutip oleh Ulber Silalahi mengatakan bahwa kegiatan analisis terdiri dari tiga alur kegiatan yang terjadi secara bersamaan, yaitu reduksi data, penyajian data, dan penarikan kesimpulan/verifikasi. ${ }^{7}$

\section{HASIL DAN PEMBAHASAN}

SMA Negeri 1 Pemali merupkan salah satu lembaga pendidikan sekolah atas yang telah melakukan berbagai upaya untuk memajukan sekolah. Berbagai bentuk kegiatan pembelajaran, baik intrakurikuler maupun ekstrakurikuler telah dilakukan untuk menciptakan sumber daya manusia yang unggul sebagai pendukung utama dalam hal pembangunan. Secara umum SMA Negeri

1 Pemali terletak di Jl. Dr. Soetomo Desa Air Duren Kecamatan Pemali, sekitar 8,9 km dari pusat pe,erintahan Kabupaten Bangka. Dalam pelaksanaan kegiatan pembelajaran, SMA Negeri 1 Pemali mempunyai visi dan misi yang bertujuan sebagai motivator dalam kegiatan belajar mengajar.

Visi SMA Negeri 1 Pemali adalah "Menciptakan generasi yang berakhlak, berkarakter, berprestasi, menguasai IPTEK dan peduli lingkungan. "Visi tersebut diterjemahkan ke dalam misi sebagai berikut.

- Meningkatkan keimanan dan ketaqwaan terhadap Tuhan Yang Maha Esa

- Menumbuhkan dan menumbuhkembangkan pendidikan berbasis karakter

- Melaksanakan pembelajaran yang kompetitif, inovatif, dan kreatif dibidang akademik dan non akademik

- Meningkatkan kepedulian warga sekolah terhadap lingkungan

Implementasi Pendidikan Karakter Melalui Program 3S (Senyum, Sapa, Salam) di SMA Negeri 1 Pemali

Berdasarkan hasil penelitian, dalam membangun sumber daya manusia yang unggul dalam berprestasi dan memiliki pribadi yang baik, SMA Negeri 1 Pemali menjalin kerja sama dengan semua komponen sekolah (kepala sekolah, guru, staf, dan peserta didik) dan secara bersama-sama menyatukan langkah untuk membangun karakter yang baik di lingkungan sekolah. Strategi yang dilakukan SMA Negeri 1 Pemali dalam mengimplementasikan pendidikan karakter melalui program 3S (senyum, sapa, salam).

\section{Program Pengembangan Diri}

1. Kegiatan Rutin Sekolah

Kegiatan rutin merupakan kegiatan yang dilakukan peserta didik dan guru secara rutin dan terus menerus. ${ }^{8}$ Di SMA Negeri 1 Pemali kegiatan rutin yang dilaksanakan seperti berikut:

- Kegiatan sambut siswa yang dilaksanakan setiap hari Senin sampai hari Kamis. Kegiatan ini dilakukan oleh guru-guru yang sudah terjadwal dengan berdiri di depan koridor sekolah menyambut siswa dengan senyum, sapa, salam.

- Pembinaan wali kelas yang dilaksanakan setiap hari Selasa sampai hari Kamis. Kegiatan ini dilakukan 15 menit sebelum bel berbunyi, kegiatan ini dilakukan oleh wali kelas dengan menberikan bimbingan serta nasihat kepada peserta didik

- Kegiatan Jumat ceria, yang mana dalam kegiatan tersebut terdapat tiga kegiatan, yaitu rohani, senam sehat, dan kegiatan bersih-bersih. Setiap antar kelas dirolling setiap minggunya

2. Kegiatan Spontan

Kegiatan spontan adalah kegiatan yang dilakukan dengan tidak terencana saat itu juga. ${ }^{9} \quad$ Kegiatan spontan yang ada di sekolah adalah warga sekolah bersikap ramah dengan senyum dan sapa ketika bertemu dengan warga sekolah yang lain, peserta didik bersalaman serta mengu capkan salam dengan guru ketika bertemu, dan guru-guru saling senyum dan sapa ketika bertemu guru lain. Kegiatan spontan yang dilaksanakan oleh sekolah akan mengembangkan nilai toleransi peserta didik. Dengan kegiatan

\footnotetext{
${ }^{6}$ Lexy J. Moleong, Metodologi Penelitian Kualitatif, (2011): 6

${ }^{7}$ Ulber Silalahi, Metode Penelitian Sosial, (2009): 339

${ }^{8}$ Heri Gunawan, Pendidikan Karakter Konsep dan Implementasi, (2012):195
} 
spontan tersebut peserta didik akan bersikap dan bertindak saling menghargai perbedaan sesama dan menghargai sikap orang lain yang berbeda dengan dirinya.

3. Keteladanan

Dalam kegiatan keteladanan, bentuk keteladanan dari program 3S (senyum, sapa, salam) adalah yang pertama kepala sekolah berjabat tangan dengan guru dan staf ketika baru datang ke sekolah, kedua guru saling bersalaman dengan guru yang lainnya ketika sampai di sekolah, dan ketiga guru-guru dan staf bersalaman selepas upacara bendera pada hari senin. Ini merupakan contoh yang baik untuk peserta didik. Dengan keteladanan yang diberikan oleh kepala sekolah, guru, dan staf maka peserta didik secara tidak langsung akan mencontohkannya. Hal ini dapat mengembangkan nilai toleransi dan cinta damai dalam diri warga sekolah.

4. Pengkondisian

Di dalam pengkondisian terdapat dua kegiatan, yaitu dengan cara mensosialisasikan program $3 \mathrm{~S}$ (senyum, sapa, salam) dan memasang slogan $3 \mathrm{~S}$ (senyum, sapa, salam)

\section{Program 3S (senyum, sapa, salam) dalam Mata Pelajaran}

Dalam kegiatan pembelajaran untuk melaksanakan pendidikan karakter dapat dilakukan dengan menggunakan pendektakan kontekstual. Melalui pembelajaran kontekstual peserta didik mengaitkan materi dengan situasi dunia nyata. Dengan begitu, melalui pembelajaran kontekstual peserta didik lebih memiliki hasil komprehensif tidak hanya pada tataran kognitif (olah pikir), tetapi pada tataran efektif (olah hati, rasa, dan karsa) serta psikomotor (olah raga). ${ }^{10}$ Untuk program $3 S$ (senyum, sapa, salam) yang dilaksanakan ke dalam mata pelajaran, guru telah mencantumkan nilai yang akan dikembangkan serta mencantumkan kegiatan 3S (senyum, sapa, salam) ke dalam Rencana Pelaksanaan Pembelajaran (RPP) walaupun kebanyakan kegiatan ini lebih dilakukan secara spontan oleh guru.

\section{Program $3 S$ (Senyum, Sapa, Salam) yang dilaksanakan dalam Kegiatan Ekstrakurikuler}

Untuk budaya sekolah SMA Negeri 1 Pemali Kecamatan Pemali Kabupaten Bangka mengintegrasikan program 3S (senyum, sapa, salam) kedalam kegiatan ekstrakurikuler seni tari. Adapun kegiatan program 3S (senyum, sapa, salam) dalam kegiatan ekstrakurikuler yang pertama adalah guru memulai kegiatan tari dengan salam yang dilanjutkan dengan bersalaman. Kedua guru menyiapkan peserta tari untuk menari dan membukanya dengan salam sambil tersenyum. Ketiaga guru mengajar peserta didik dengan senyum dan mengajarkan tari yang memiliki segi positif.

Guru mengajari peserta didik dengan lembut dan tersenyum. Tarian yang dibawakan merupakan tarian tradisional yang berasal dari Bangka Belitung yang mempunyai gerakan yang luwes dan sopan. Hal ini dapat membantu peserta didik membiasakansikap murah senyum dan sopan santun melalui pembelajaran gerakannya.

\section{Faktor-faktor Pendukung dan Penghambat dalam Pelaksanaan Pendidikan Karakter Melalui Program 3S (Senyum, Sapa, Salam)}

Program sekolah tidak terwujud dengan begitu saja, tetapi juga dipengaruhi oleh faktor-faktor tertentu. Adapun dari hasil wawancara dengan guru koordinator porgram 3S (senyum, sapa, salam) faktor yang menjadi pendukung dan penghambat dalam pelaksanaan pendidikan karakter melalui program $3 \mathrm{~S}$ (senyum, sapa, salam) di SMA Negeri 1 Pemali sebagai berikut:

1. Faktor pendukung, yaitu keefektifan kegiatan belajar mengajar, adanya sumber daya guru dan lingkungan yang baik, dan guru yang mudah dan cekaran untuk diarahkan.

2. Faktor penghambat, yaitu kurangnya kesiapan beberapa guru, siswa masih ada yang belum disiplin, dan faktor cuaca.

\section{KESIMPULAN}

Berdasarkan hasil penelitian, peneliti dapat menyimpulkan bahwa dalam implementasi pendidikan karakter melalui program 3S (senyum, sapa, salam), bahwa:

1. Program 3S (senyum, sapa, salam) merupakan program yang didasarkan atas visi dan misi sekolah yang ditetapkan dalam Surat Keputusan. Program 3S (senyum, sapa, salam) dilaksanakan dalam program pengembangan diri yang meliputi, kegiatan rutin sekolah, kegiatan spontan, keteladanan, dan pengkondisian. Kemudian program 3S (senyum, sapa, salam) dilaksanakan dalam mata pelajaran, dan dilaksanakan dalam kegiatan ekstrakurikuler. Nilai karakter yang dikembangkan dalam program 3S (senyum, sapa, salam) adalah disiplin, toleransi, peduli sosial, dan cinta damai, dan bersahabat/komunikatif. 
2. Dalam pelaksanaan pendidikan karakter melalui program 3S (senyum, sapa, salam) terdapat ada beberapa faktor yang menjadi pendukung dan penghambat dalam pelaksanaannya. Berikut faktor pendukung dan penghambat serta upaya mengatasi faktor penghambat dalam pelaksanaan pendidikan karakter melalui program 3S (senyum, sapa, salam). Faktor pendukung dari program 3S (senyum, sapa, salam) adalah Pertama keefektifan kegiatan belajar mengajar, kedua adanya sumber daya guru dan lingkungan yang baik, ketiga guru yang mudahdan cekatan untuk diarahkan. Kemudian faktor penghambat daro program 3S (senyum, sapa, salam) adalah kurangnya kesiapan beberapa guru, siswa masih ada yang tidak disiplin dan cuek dengan $3 \mathrm{~S}$ (senyum, sapa, salam), dan faktor cuaca. Adapun upaya untuk mengatasi faktor penghambat dari program 3S (senyum, sapa, salam) adalah dengan cara menegur, selalu mengingatkan peserta didik, dan guru selalu memberi teladan tentang program $3 \mathrm{~S}$ (senyum, sapa, salam)

\section{REFERENSI}

Ahmadi, Rulam. 2014. Metodologi Penelitian Kualitatif. Yogyakarta: Ar-Ruzz Media.

Amazona, Rosalin Helga. 2016. "Implementasi Pendidikan Karakter di Sekolah Dasar Islam Terpadu Hidayatullah Yogyakarta" Skripsi. Fakultas Teknik Universitas Negeri Yogyakarta.

Ardan, Fatmawaty. 2017. "Implementasi Pendidikan Karakter dalam Proses Pembelajaran Matematika Pada Kelas VIII SMP Negeri 2 Sungguminasa", Skripsi. Fakultas Tarbiyah dan Keguruan Universitas Alauddin Makassar

Media.

Azzet, Akhmad Muhaimin. 2011. Pendidikan yang Membebaskan. Yogyakarta: Ar-Ruzz

Departemen Pendidikan Nasional. 2008. Kamus Besar Bahasa Indonesia.

Jakarta: Balai Pustaka.

Gunawan, Heri Gunawan. 2012. Pendidikan Karakter Konsep dan Implementasi.

Bandung: Alfabeta.

Moleong, Lexy J. 2011. Metodologi Penelitian Kualitatif. Bandung: Rosdakarya.

Muslich, Masnur. 2011. Pendidikan Karakter Menjawab Tantangan Krisis Multidimensional. Jakarta: Bumi Aksara, 2011.

Salim, Moh. Haitami. 2013. Pendidikan Karakter. Yogyakarta: Ar-ruz Media.

Sarwono, Jonathan. 2006. Metodologi Penelitian Kuantitatif dan Kualitatif. Yogyakarta: Graha Ilmu.

Soyomukti, Nurani. 2015. Teori-teori Pendidikan. Yogyakarta: Ar-Ruzz Media.

Sugiyono. 2008. Metode Penelitian Pendidikan (Pendekatan Kuantitatif, Kualitatif, dan R\&D). Bandung: Alfabeta.

Suparno, Paul. 2015. Pendidikan Karakter di sekolah. Depok: PT Kanisius. 